\title{
Reasons for Insufficient Demand of Environmental Liability Insurance in China_-A Case Study of Baoding, Hebei Province
}

\author{
Congjun Liu ${ }^{1,2} \&$ Abdul Razak Bin Chik $^{2}$ \\ ${ }^{1}$ College of Economics, Hebei University, Baoding, China \\ ${ }^{2}$ School of Economics, Finance and Banking, College of Business, Universiti Utara Malaysia, Kedah, Malaysia \\ Correspondence: Congjun Liu, College of Economics, Hebei University, Baoding, Hebei, China. Tel: \\ 60-17-416-6910. E-mail: zhbxxn@163.com
}

Received: May 8, 2012 Accepted: July 8, 2012 Online Published: September 20, 2012
doi:10.5539/ass.v8n12p201 $\quad$ URL: http://dx.doi.org/10.5539/ass.v8n12p201

This study is sponsored by Hebei Education Department. Project Title: The Development Strategy of Environmental Liability Insurance in Hebei Province. Project Number: SZ2011501

\begin{abstract}
Environmental liability insurance is one of the "green policies" adopted by China government to deal with the deteriorating environmental pollution problem. Although there has been some development of it due to government pushing, the product is still not very attractive to potential polluters. This study looks into this problem and aims at finding reasons for it and making some development suggestions by conducting in-depth interviews in Baoding, Hebei province in China.
\end{abstract}

Keywords: environmental liability insurance, legal system, alternative risk management tool, coverage, pricing

\section{Introduction}

Accidental contamination has become a serious problem these years in China. As reported in the Bulletin of Environmental Situation of China in 2010, 420 accidental environment pollution events have been reported to the Ministry of Environmental Protection of the People's Republic of China.

Among many policies dealing with environmental pollution problems, environmental liability insurance is deemed to be an effective method in relieving environmental problems through modern insurance system. Since 1960 's, the environmental liability insurance has been put into practice in many western developed countries such as United States, Germany, Sweden, Finland, the United Kingdom and France.

Many researchers agreed that environmental liability insurance is an effective method to deal with environmental problem through many ways. For examples, it can play an important role in brownfield sites cleanup and reuse (Anderson \& Harrington, 2006); it is an appropriate remedy for the problem of underdeterrence caused by insolvency of the injurers (Faure, 2002); and it would be more efficient to improve environment because it allows regulators to depend on a market-based mechanism (Cuddihy, 2000).

Environmental liability insurance also becomes a hot issue in China. On June 17, 2011, the 7.5th international conference on liability insurance was held in China with the theme of "exploring environmental liability insurance in China". Delegates from the Ministry of Environmental Protection, insurance companies, insurance associations, colleges and universities had a heated discussion on the role of insurance and reinsurance companies in dealing with environmental liability risks as well as the proper developing mode of environmental liability insurance in China.

Many researchers in China also agree that environmental liability insurance has some positive effects such as ensuring the injured getting their compensation in case of pollution accident, relieving polluter from financial collapse, etc.( Liu,2006; Luo \& Wu, 2009; Teng, 2010). However, the development of environmental liability insurance in China has not been satisfactory since it was first introduced in the city of Dalian in 1991.

In 1980, China joined the "International Convention on Civil Liability for Oil Pollution Damage, 1969". According to the Convention, "the owner of a ship registered in a Contracting State and carrying more than 2,000 tons of oil in bulk as cargo shall be required to maintain insurance or other financial security..." Therefore, 
environmental liability insurance becomes compulsory for oil pollution damage liability in China. Environment pollution liability insurance in other fields started much later and the development of it can be divided into two phases:

In the early 1990s, environmental liability insurance was introduced in Dalian, Changchun, Shenyang and some other cities. However, very few enterprises showed interest in such insurance product. The attempt ended with low insurance rate and premium income. Since 1991 to 1994, only 15 firms purchased environmental liability insurance in Dalian with a premium income of CNY 2.2 million. In 1992, only one firm purchased environmental liability insurance in Changchun.

The second phase is from 2007. In 2007, Ministry of Environmental Protection and the Insurance Regulatory Commission jointly issued "Environmental Pollution Liability Insurance Guidance" and proposed to establish environmental liability insurance system during the "Eleventh Five-Year" period and extend it nationwide by 2015. Nevertheless, Hunan, Jiangsu and other regions piloting environmental liability insurance in China didn't see satisfactory result. Despite the vigorous cooperation of local environmental protection department and insurance companies in promoting it, desire for purchasing environmental liability insurance is still dull. The number of insured keeps zero in some cities. Compared with other insurance products, demand for environmental liability insurance is obviously not sufficient to meet the requirement of law of large numbers.

Many researchers expressed their opinion on this. The lack of relevant law, the potential polluter's underestimate of their risks, the limited coverage of the insurance and the high price are deemed to be the main reasons for the unsatisfactory development of environmental liability insurance in China (Luo \&Wu, 2008; Teng, 2010). However, no detailed explanation or analysis has been provided about these arguments. For example, does environmental liability risk really underestimated by the potential polluter? Is there any different opinion about environmental liability insurance among risk managers and why? In order to get more meaningful information about the reasons why potential polluters in China have little interest in purchasing environmental liability insurance, in-depth interviews were conducted in Baoding, Hebei Province of China involving 23 firms facing environmental liability risks. Through this approach we drew clearer and much more detailed ideas about the reasons why environmental liability insurance product is presently not attractive to potential polluters in China.

\section{Method}

In-depth interviews, conducted July-August 2011, involved 23 respondents who are actually in charge of risk management of the sample firms facing environmental liability risks. These people may be risk manager, CEO or owner of the firm. To ensure the validity of the information collected during these interviews, it was made clear to the respondents that the objective of the interview was just for academic research and no recorder was going to be used to make them feel at ease.

However, before conducting the interviews, desk study was done to get information about the enterprises where the respondents work and the necessary background about the respondents themselves. The information collected before conducting the interviews includes the size of the enterprise, the source of the potential pollution, and the education background of the respondents.

\section{Results}

It was clear that very few respondents are interested in such insurance products. The typical and initial response is like this:

Why do I need such a thing?

Specifically, the main reasons are:

\subsection{Lacking Awareness of the Liability Risk}

Lacking awareness of the liability risk is the biggest problem. Most of the respondents are not aware about the potential pollution risk, especially when it comes to the concept of liability.

I know there would be a big loss if pollution accidents happened, but do you think it will really happen? I didn't see any accident for decades.

..., even if it happened, I do not think the injured can bring a lawsuit against us. The only one thing I worry about is the pressure from the regulator...

These responses are mostly from small and medium size enterprises. However, no respondent from these enterprises mentioned anything about the famous underdeterrence problem caused by insolvency. It seems that they don't worry the potential pollution liability at all, so there is obviously no need to think about the possibility 
to go into insolvency because of pollution liability.

\subsection{Alternative Risk Management Tools}

Some respondents mentioned other choices of approaches to manage their pollution liability risk.

I think our company is financially powerful enough to deal with this kind of problem. As a matter of fact, we have established a special fund for such risk.

This response is from a chief risk manager of a large enterprise. It is understandable because if an enterprise is big enough, it can self-insure itself against its pollution liability exposure.

Some other responses are like this:

Our company has paid a deposit according to the requirement of the regulator, why should we buy such an insurance product in addition to that?

It seems like an overlap although they have different emphasis and this should be taken into consideration when developing the insurance product.

\subsection{Unsatisfactory Product}

What can not be ignored also include the complaints about the unsatisfactory product.

I didn't see any point to buy such a product. I mean the major pollution risk we might encounter is in the middle of delivery. However this risk has been exempted from the environmental liability insurance.

I think the most important risk our company concern about is the liability coming from gradual pollution...

It is obvious that a lot of complaints are about the limited coverage of environmental liability insurance. Nowadays, in China, only a few insurance companies provide environmental liability insurance products which only cover liabilities rising from accidental events that occur on the insured's manufacturing site.

Besides coverage, complain about high premium rate can also be heard.

The premium rate is too high. Our company only makes a little profit. This is a big burden on us.

Most complaints about high premium rate are from small size or medium enterprises. However some respondents from large companies also complained about it because they think they pay too much compared to their risks.

I don't think we should pay so much for this. Why they charge us according to the size. Big size doesn't necessarily mean high risk...

The method of determining premium is really a big problem nowadays. Basically, premium rate should be set according to the loss probability. However it is still very difficult for the insurer to get enough historical data about it. Furthermore, even if the premium rate has been set at an appropriate level as a whole, the exposures differentiate from firm to firm. Compared to those facing serious problems, enterprises with low-level risks would not like to purchase such insurance product, which might lead to the adverse selection problem.

\section{Discussion and Suggestions}

The studies reported in this paper were limited in scope and used small purposive sampling. However, some conclusions can be drawn and on base of it some suggestions can be made.

\subsection{Improving Relevant Legal System}

It is clear that the present legal system in China should be blamed a lot for the insufficient demands of environmental liability insurance. How can a product aiming at relieving the liability be popular when there are not clear and strict rules for such "liability"? This is also one of the main arguments proposed by some researchers arguing for compulsory environmental liability insurance, although this argument is hardly holding because we can always develop legal system instead of implementing environmental liability insurance by force. So some other reason would be needed for arguing for compulsory environmental liability insurance, which would be another issue. However there is one thing we know for sure that there should be clear definition of environmental liability in law and the law should be implemented fully to motivate demand of environmental liability insurance. However, law improvement cannot be expected to be finished in a short time to motivate immediate demand for environmental liability insurance, which explains why government administrative means are resorted to in many places where environmental liability insurance is being piloted. For example, in Baoding, Hebei province, environmental liability insurance is required for some industries to pass their annual verifications. 


\subsection{Developing Alternative Risk Management Tools}

Environmental liability insurance is only one of the tools that are used to deal with pollution liability exposures. The essence of it is transferring the environmental liability risk from the insured to the insurer. Besides insurance company, there are other alternative risk carriers, captives, for example. Captives are some special risk carriers usually established by some large companies which mainly take in the risks from its mother company. Another example is bond. For some industries, pollution cleaning bonds are required by the regulation before being allowed to enter the industry.

When promoting environmental liability insurance, all of these risk management methods should be taken into consideration. If it could be proved that it was more efficient to transfer risks to an alternative risk carrier than a traditional insurance company, this alternative risk carrier should be acceptable when environmental liability insurance is required by the regulator. Furthermore, if bond has been required for an industry, although it is usually for public liability, it should be taken into consideration when calculating premium because at present, the environmental liability insurance product in China cover both civil and public liabilities. Duplicate should be avoided.

\subsection{Developing Better Products}

A conclusion can be drawn from the information collected in the interviews. The environmental liability insurance products provided by insurance companies presently can hardly meet the demand of the potential polluters. Most complains come from on the coverage and pricing of this product. If product pricing problem can be deemed to be a knotty problem due to the intrinsic characteristics of environmental liability risks, at least coverage problem can be sorted out to some extent. For example, risk rising from delivery can be covered as appending risk if it is not covered by any other insurance product. And for some special industry, petroleum, for instance, gradual risk should be taken into consideration because one of the main risks is from oil leakage.

As for pricing, although premium rate has to be set at a comparatively high level to ensure the insurer's safety because of lacking enough loss data at present, there is still something can be done to make the premium more reasonable and acceptable. First of all, the risk level of the insured must be taken into consideration. Although it is very difficult or almost impossible for an insurer to assess insured's risks in every detail, it can adopt some more specific hazard rating system. For example, at present the premium rate can be adjusted only according to source material classification, however at least location of the insured should be taken into consideration. Furthermore, the deductible should be more flexible according to the demand of the insured. Larger company can enjoy higher deductible and less premium level if it wants to because it is less likely for large company to become insolvency unless confronting a huge loss.

In conclusion, there are many reasons for the insufficient demand for environmental liability insurance in China nowadays. That is why many researchers argued for compulsory insurance to make this "green policy" develop smoothly in China. Whereas compulsory insurance also has its disadvantages, more studies should be done before adopting it. And even if compulsory insurance was adopted, products should be improved to meet insured's demand.

\section{Acknowledgements}

This study was carried out when the author worked along with other experts for promoting environmental liability insurance in Baoding, Hebei province. We would like to thank the people who participated in this study, Baoding Changcheng Brokerage Company as well as the Agency of Environmental Protection of Baoding that has assisted this study.

\section{References}

Anderson, K., \& Harrington, A. (2006). Environmental insurance can reduce liability risk at brownfield sites. Hazardous Waste Consultant, 24(4).

Cuddihy, T. (2000). Environmental liability risk management for the 21st century. The Geneva Papers on Risk and Insurance, 25(1), 128-135. http://dx.doi.org/10.1111/1468-0440.00053

Faure, M. G. (2002). Environmental damage insurance in theory and practice. In Timothy Swanson (Ed.), Research in Law and Economic (Vol. 20, pp. 283-328). Emerald Group Publishing Limited.

Liu, J. (2006). The importance and possibility of developing environmental liability insurance in China. Ecological Economy, 5,145-147.

Luo, M., \& Wu, S. K. (2008). Analysis on present situation of environmental liability insurance in China and the prospects of its system. Journal of Insurance Professional College (Bimonthly), 22(2), 10-14.

Press, C. L., \& Bixler, A. G. (2002). Environmental insurance can address liability problems, if businesses lay the groundwork. Adhesives \& Sealants Industry, 13, 20-22.

Teng, J. (2010). Probe into New Measures for Environmental Economic Policy, Environmental Pollution Liability Insurance. China Environmental Protection Industry, 5, 10-13. 